\title{
RESEARCH ON KEY POINTS OF QUALITY INSPECTION OF AERIAL PHOTOGRAMMETRY RESULTS AND QUALITY IMPROVEMENT MEASURES
}

\author{
Tian Zongbiao ${ }^{1}$, Li Miao $^{1}$, Lv Linbing $^{1}$, Zhou Jin $^{1}$ \\ ${ }^{1}$ National Quality Inspection and Testing Center for Surveying and Mapping Products, Beijing, China -(526859986, 9105513, \\ 1194081025, 1033486498)@qq.com
}

KEY WORDS: Aerial Photography, Quality, Problem Analysis, Evaluation Criteria, Industry, Improvement Measures.

\begin{abstract}
:
With the development of surveying and mapping geographic information technology, digital aerial photogrammetry technology has been widely developed and applied. Based on the research on the applicability of existing quality inspection standards, this paper has completed the analysis of the key points of the quality inspection of surveying and mapping aerial photography results on the current technological development level, and combined with the quality inspection work of related projects for many years, selecting 15 real cases in the industry from the technology, it completed the analysis of common quality problems in four aspects: flight quality, data quality, image quality, and accessory quality, and put forward relevant quality evaluation standards and suggestions for improving production quality. The research content of the article can provide a reference for the production and quality inspection of corresponding projects in the later period, and provide a basis for industry supervision and promote the improvement of the overall quality level of the industry.
\end{abstract}

\section{INTRODUCTION}

Digital aerial photography achievements are divided into frame type and push-broom type. With the continuous deepening of theoretical research by the scholars around the world, technologies and applications have also been greatly developed (Tang et al,. 2012a; Geng, et al., 2010a; Hhle, 2009a).

The requirements for high quality of results increase gradually as the rapid strengthening of technical theories and continuous expansion of the application fields. It is important to analyze the key points of quality inspection of digital aerial photogrammetry results, and combine the current industry status to analyze common problems in project results (Hong et al., 2013a). In this case, this paper centers on the key points of quality inspection on digital aerial photography data. The common quality problems, according to quality standards, are studied and analysed based on the 15 relevant projects.

\section{BASIS ANALYSIS FOR QUALITY INSPECTION}

At present, the quality inspection basis of surveying and mapping results mainly refers to the "Quality Inspection and Acceptance of Surveying and Mapping Results" (GB/T 243562009). This standard uses a weighted average model to achieve quality inspection and evaluation of aerial photography results. In terms of data quality and accessory quality, the inspection items, the division of quality elements, the weighting ratio, the enumeration of errors and omissions are regulated. The standard has been widely used since its promulgation and implementation in 2009, and has been used in promoting the quality of results and scientific evaluation It played an important role.

With the continuous development of technology, especially the application of digital operation methods, some of the contents of GB/T 24356-2009, which focuses on the quality inspection and acceptance of traditional photogrammetric results, show signs of lagging behind technological development, such as the quality of processing and the quality of scanned data. It is no longer used in the results of direct digitization, and the quality of POS data is also not specified in the standard.

In this context, in order to meet the needs of industry quality work, "Aerial Photography Achievement Quality Inspection Technical Regulations Part 2: Frame Digital Aerial Photography" (CH/T 1029.2-2013)and "Aviation Technical Regulations for Quality Inspection of Photographic Achievements Part 3: Push-broom Digital Aerial Photography"( CH/T 1029.3-2013), the inspection content is divided into four parts: flight quality, data quality, image quality and accessory quality, and the inspection is carried out according to production methods, quality control points, etc. Internal use and weight are distinguished. The detailed division and check items of frame digital aerial photography results and push-broom digital aerial photography results are shown in Table 1 and Table 2.

\begin{tabular}{|c|c|c|c|}
\hline \multicolumn{4}{|c|}{ Frame type } \\
\hline \multirow{2}{*}{$\begin{array}{l}\text { Quality } \\
\text { element }\end{array}$} & \multicolumn{2}{|c|}{ Weights } & Inspection content \\
\hline & I & II & Check item \\
\hline \multirow{9}{*}{$\begin{array}{l}\text { Flight } \\
\text { quality }\end{array}$} & \multirow{9}{*}{0.35} & \multirow{9}{*}{0.25} & Aerial photography design \\
\hline & & & Photo overlap \\
\hline & & & Cover integrity \\
\hline & & & Photo tilt angle \\
\hline & & & Course curvature \\
\hline & & & Deflection angle \\
\hline & & & track \\
\hline & & & Image point displacement \\
\hline & & & Altitude maintenance \\
\hline \multirow{4}{*}{$\begin{array}{l}\text { Image } \\
\text { quality }\end{array}$} & \multirow{4}{*}{0.4} & \multirow{4}{*}{0.35} & Exterior \\
\hline & & & Geometric accuracy \\
\hline & & & Image stitching \\
\hline & & & Image integrity \\
\hline \multirow[b]{2}{*}{$\begin{array}{l}\text { Data } \\
\text { quality }\end{array}$} & \multirow[b]{2}{*}{0.15} & \multirow[b]{2}{*}{0.3} & Image data \\
\hline & & & $\begin{array}{l}\text { GNSS (or IMU/GNSS) } \\
\text { related numbers }\end{array}$ \\
\hline
\end{tabular}

\footnotetext{
* Corresponding author
} 


\begin{tabular}{|c|c|c|c|}
\hline \multicolumn{4}{|c|}{ Frame type } \\
\hline \multirow{2}{*}{$\begin{array}{l}\text { Quality } \\
\text { element }\end{array}$} & \multicolumn{2}{|c|}{ Weights } & Inspection content \\
\hline & I & II & Check item \\
\hline \multirow{4}{*}{$\begin{array}{l}\text { Attachmen } \\
\text { t quality }\end{array}$} & \multirow{4}{*}{0.1} & \multirow{4}{*}{0.1} & Technical documents \\
\hline & & & Verification data \\
\hline & & & Finishing packaging \\
\hline & & & Figures and schedules \\
\hline \multicolumn{4}{|c|}{$\begin{array}{l}\text { Remarks: } \\
\text { I - - Digital aerial photography } \\
\text { II - - GNSS (or IMU/GNSS) assisted digital aerial } \\
\text { photography }\end{array}$} \\
\hline
\end{tabular}

Table 1. Quality elements and rights of digital aerial photography results(Frame type)

\begin{tabular}{|c|c|c|}
\hline \multicolumn{3}{|c|}{ Push-broom } \\
\hline Quality element & Weights & Check item \\
\hline \multirow{6}{*}{ Data quality } & \multirow{6}{*}{0.4} & Image data \\
\hline & & $\begin{array}{l}\text { Aerial camera parameter } \\
\text { file }\end{array}$ \\
\hline & & Eccentric component \\
\hline & & GNSS data \\
\hline & & IMU data \\
\hline & & $\begin{array}{l}\text { IMU/GNSS fusion } \\
\text { processing results }\end{array}$ \\
\hline \multirow{8}{*}{ Flight quality } & \multirow{8}{*}{0.3} & Aerial photography design \\
\hline & & General side lap \\
\hline & & Cover integrity \\
\hline & & Course curvature \\
\hline & & Flying attitude \\
\hline & & track \\
\hline & & Ground speed \\
\hline & & Altitude maintenance \\
\hline \multirow{2}{*}{ Image quality } & \multirow{2}{*}{0.2} & Exterior \\
\hline & & Image integrity \\
\hline \multirow{4}{*}{$\begin{array}{l}\text { Attachment } \\
\text { quality }\end{array}$} & \multirow{4}{*}{0.1} & Technical documents \\
\hline & & Verification data \\
\hline & & Finishing packaging \\
\hline & & Figures and schedules \\
\hline
\end{tabular}

Table 2. Quality elements and rights of digital aerial photography results(Push-broom)

\section{ANALYSIS OF KEY POINTS OF QUALITY INSPECTION}

\subsection{Inspection Method}

(1) General inspection

The overall inspection of flight quality (aerial photography design) is mainly carried out by means of verification analysis and comparison analysis.

In contrast to the requirements of aerial photography contracts, design documents, etc., verify the accuracy indicators of the basic geographic data used in the design, the selection of the season and time of aerial photography, the selection of aerial photography systems, the layout and data processing of the inspection site, the division of aerial photography, the direction of aerial photography and the laying method, Ground resolution, etc. are consistent with the requirements of the contract and design.

\section{(2) Sample detailed inspection}

The detailed inspection of flight quality, image quality, data quality and accessory quality is mainly carried out by means of verification analysis and comparison analysis.

\section{1) Flight quality}

According to the aerial photography contract, design document and related standards, use the inspection software to check the heading overlap, side overlap, and tilt angle of the photo, rotation angle, course curvature, image point displacement and flight height difference, check whether it meets the design and specification requirements.

Check the aerial photography coverage area against the requirements of the aerial photography contract, design document, etc., load the boundary data from reliable sources, import the boundary range point or surface, compare the range with the POS data like the main point, and check whether the range of the photography area meets the contract requirements, And check for aerial photography loopholes by means of verification.

\section{2)Image quality}

The appearance of the image uses human-computer interaction to check whether the sharpness, cloud shadow, and color of the image meet the quality requirements; the geometric accuracy uses a relative orientation method to sample the geometric accuracy of the image to check whether the relative orientation accuracy meets the requirements and whether the relative orientation points are uniform Covers the entire overlapping area; image stitching uses human-computer interaction to check whether there is misalignment, blur, ghosting, etc.; image integrity uses software to check whether there are missing bands, image occlusion, invalid pixels, etc.

\section{3)Data quality}

Check the completeness and completeness of the image data; check the integrity of the GNSS auxiliary aviation flight record, check the correctness of the observation data and the format and naming of the solution file; if necessary, compare and analyze the GNSS solution by recalculating The accuracy of the data.

\section{4) Attachment quality}

In accordance with the aerial photography contract, design document and related standards, check the completeness and completeness of technical documents; check the camera verification parameter report, ground base station and airborne GNSS receiver verification report, and IMU equipment verification report for completeness and compliance; verification The completeness and correctness of the contents of the various drawings and attached tables.

\subsection{Check points}

\section{1) Airspace application documents}

My country's low-altitude airspace control has gradually opened up and drone technology has developed rapidly. According to the "General Aviation Flight Control Regulations" and other laws and regulations, high-altitude flights need to apply to relevant departments for flight plans and flight areas. In recent years, the punishment for "black flight" has gradually increased, 
From the perspective of security only, this content inspection is of great significance to the promotion of industry management, etc. The inspection method is relatively simple, so I will not repeat it in this article.

\section{2)Flight quality}

Flight quality generally includes heading overlap, side overlap, photo tilt angle, rotation angle, course curvature, image point displacement, and flight height difference. This part of the content is generally checked by software. The difficulty is based on The inspection results are evaluated for quality.

According to the standard, when any one of the flight quality inspection parameters exceeds the limit and the next process cannot be operated, the result is unqualified. Therefore, a comprehensive assessment should be made based on the purpose of using the aerial photography results and whether the next process is carried out, despite the production standard All indicators are clearly stipulated. At the current technical level, as long as there is no serious flight quality and a large proportion of overruns, it is difficult to cause the next process to fail. The author believes that the focus is to determine the resolution based on the overrun of the above indicators. The resulting impact is used as a measurement factor. In terms of line height maintenance, the application of variable altitude flight has been carried out in individual projects, especially in areas with large terrain undulations such as the $\mathrm{ft}$ zone. Due to the strictness of the standard formulation process, it is difficult for quality inspection standards to follow closely in time. Adjustments due to technological advancement have put forward higher requirements for the appraisal work of quality inspectors in terms of grasping standards, which cannot be dealt with in accordance with standard "dogmatics".

The aerial photography coverage area is mainly completed by comparing the range boundary data with the POS data like the main point. When checking, be sure to load the reliable boundary data according to the project contract. When the first inspection finds a problem, check that the POS data is solved correctly Based on the existing original observation data, it can be recalculated using GNSS data settlement software, etc.

\section{3) Image quality}

On the basis of using quality inspection software to check, manually check the resolution, image blur, cloud, cloud shadow, smoke, etc. The focus is on whether the error or omission makes it difficult to determine the ground feature, so as to evaluate whether it is suitable for the next process. Part of the content still needs to be determined based on the purpose of use of the project results. For example, for the purpose of censoring roads or residential areas, if the image quality appears in the $\mathrm{ft}$ area and other places, even if the type of features cannot be distinguished, the types of errors and omissions can be appropriately reduced.

\section{QUALITY PROBLEM ANALYSIS AND QUALITY IMPROVEMENT MEASURES}

In recent years, with the advancement of aerial photogrammetry technology and the continuous improvement of market demand, more and more surveying and mapping companies are engaged in aerial photogrammetry activities. For this reason, in order to estimate the current quality of the industry, the author collected 15 aerial photography projects The result quality inspection situation, the 15 units are distributed in 15 provinces including
Guangdong, Guangxi, Hunan, Hebei, Henan and other Grade A units, and they are projects completed in recent years.

Through the human-computer interaction inspection method, according to the methods and content described above, the corresponding general problems have been summarized and sorted out.

In accordance with the scoring method of GB/T 24356, each project completes the quality sub-elements, quality elements, unit results, and standard requirements in sequence. Different types of errors and omissions are classified into A, B, C, and D. The detailed rules for deductions for quality errors and omissions are shown in the table below.

The judgement of errors and omissions of quality sub-elements shall be carried out in accordance with relevant standards. The scoring method for quality sub-elements is as follows:

$$
S_{2}=100-\left[a_{1} \times(12 / t)+a_{2} \times(4 / t)+a_{3} \times(1 / t)\right]
$$

In the formula:

$\mathrm{a}_{1}, \mathrm{a}_{2}, \mathrm{a}_{3}$ - the corresponding number of class B, class $\mathrm{C}$, and class D errors in the quality sub-elements.

$\mathrm{S}_{2}$ - The score value of the quality sub-element. $\mathrm{t}$-Difficulty factor, 1 when normal.

\begin{tabular}{|c|c|}
\hline Error type & Demerit value \\
\hline Class A & 42 \\
\hline Class B & 12 \\
\hline Class C & 4 \\
\hline Class D & 1 \\
\hline
\end{tabular}

Table 3. Standards for deducting points for quality of results

The weighted average method is used to calculate the quality element score:

$$
S_{1}=\sum_{i=1}^{n}\left(S_{2 i} \times p_{i}\right)
$$

Where:

$\mathrm{S}_{1}$ - Quality element score value;

$\mathrm{S}_{2 \mathrm{i}}$ - The score value of the i-th quality sub-element in the quality element;

$\mathrm{p}_{\mathrm{i}}$ - The weight of the ith mass sub-element in the mass element;

$\mathrm{n}$ - The number of mass sub-elements contained in the mass element.

The weighted average method is used to calculate the unit achievement quality score:

$$
S=\sum_{i=1}^{n}\left(S_{1 i} \times p_{i}\right)
$$

Where:

S - Quality score value of unit achievement;

$\mathrm{S}_{1 \mathrm{i}}$ - The score value of the i-th quality element;

$\mathrm{p}_{\mathrm{i}}$-The weight of the $\mathrm{i}$-th quality element;

$\mathrm{n}-$ The number of quality elements contained in the unit result.

Calculate sample quality score by arithmetic average, the final result quality score statistics of 15 projects are shown in Figure 1.

Select representative quality issues from aspects such as flight quality, impact quality, and data quality. 


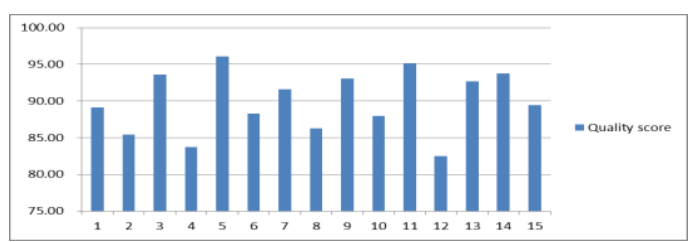

Figure 1 . The 15 project quality score statistics table

(1) Flight quality

In the flight quality inspection index, the heading overlap degree should generally be $60 \%$ 65\%, the minimum should not be less than $53 \%$, and the side overlap degree should generally be $20 \%$ 30\%, the individual minimum should not be less than $13 \%$; the inclination angle of the photo should generally not be greater than $2^{\circ}$, and the maximum of 1:500 1:2000 should not be greater than $4^{\circ}, 1: 5000 \sim 1: 50000$, the maximum survey map should not be greater than $3^{\circ} ; 1: 500 \sim 1: 2000$ survey image rotation angle should generally not be greater than $15^{\circ}$, on the premise of ensuring the overlap of heading and side directions.

The maximum down angle should not be greater than $25^{\circ}$, 1:5000 1:50000, the rotation angle of the measured image should generally not be greater than $10^{\circ}$, and the maximum should not be greater than $15^{\circ}$ under the premise of ensuring the overlap of the heading and side directions; the capture boundary coverage In terms of guarantee, the heading coverage beyond the capture boundary line is not less than one baseline, and the lateral coverage beyond the capture boundary line is generally not less than $30 \%$ of the image frame; the curvature of the photo should generally not be greater than $1 \%$; adjacent photos on the same route The flight altitude difference should not be greater than $30 \mathrm{~m}$, and the difference between the maximum flight altitude and the minimum flight altitude should not be greater than $50 \mathrm{~m}$, the inspection is generally based on the principle of whether it affects the resolution.

Based on the principle of grasping the above indicators, the following problems have occurred in flight quality inspection:

1)The heading overlap exceeds the limit;

2)The inclination angle of the photo exceeds the limit, and the rotation angle of some photos exceeds the limit;

3)Ingestion boundary coverage-the area heading and side coverage do not meet the requirements.

Among them, if the flight altitude keeps exceeding the limit, but generally does not have a serious impact on the resolution, it is not mentioned as a quality problem. In order to reflect the specific conditions of flight quality, the statistical results of one item in the selected case are shown in Table 4, and the coverage problem is shown in Figure 2.

\begin{tabular}{|l|l|l|}
\hline General end lap & 62.317 & \\
\hline Maximum end lap & $31001 \sim 31002$ & 96.928 \\
\hline Minimum end lap & $13034 \sim 13035$ & 14.080 \\
\hline General side lap & 68.286 & \\
\hline Maximum side lap & $25008 \sim 26006$ & 97.647 \\
\hline Minimum side lap & $28003 \sim 30045$ & 23.428 \\
\hline Maximum rotation angle & $12050 \sim 12051$ & -73.774 \\
\hline Maximum course bend & 01003 & 0.605 \\
\hline
\end{tabular}

Table 4. Statistics of flight quality inspection results

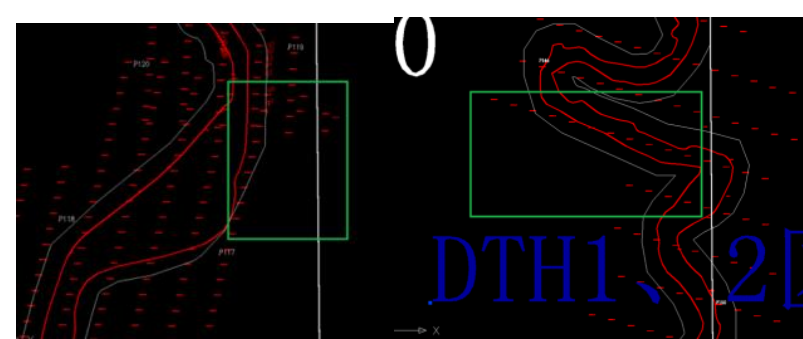

Figure 2. The route coverage area does not meet the requirements

(2) Image quality

There is no quantitative index for image quality inspection, only qualitative index requirements: the image should be clear, moderate contrast, soft tones, and must not have defects such as clouds, large-area reflections, stains, etc., the key point is to be able to identify the images of small ground objects that are compatible with the ground resolution, The quality issues are as follows:

1)Appearance: poor quality of images such as snow, clouds, cloud shadows, smoke, reflections, haze, shadows, etc.;

2)Image information loss: poor layering, insufficient saturation, too little or too much contrast. An example of image quality problems is shown in Figure 3.

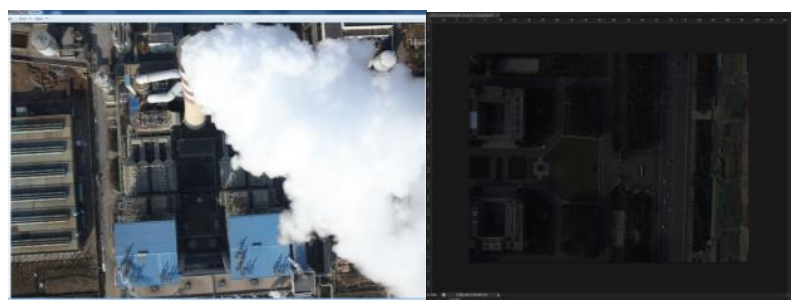

Figure 3. There is thick smoke or dark color in the photo

(3) Data quality

There is thick smoke or dark color in the photo, which affects the recognition of features

Irregular arrangement of file naming, numbering, etc.: Aerial photo numbering is not organized in accordance with relevant technical regulations.

\section{(4)Attachment quality}

1)Incomplete information: No valid aerial photograph military area approval document has been submitted;

2)Incomplete information: No aerial photographic data submission report has been submitted.

3)Incorrect or omission of the contents of the data: The contents of aerial photographing data such as aerial photographing appraisal form/ aerial photographing flight record are incorrect: for example, the records of aerial photograph quantity and aerial photograph number are inconsistent with the actual flight; the description of important indicators such as camera type, serial number and parameters is inconsistent, etc. .

According to the proportion of the items with the above problems in the overall collection items, the current quality of the industry can be analyzed to a certain extent. The proportion statistics are shown in Figure 4. 


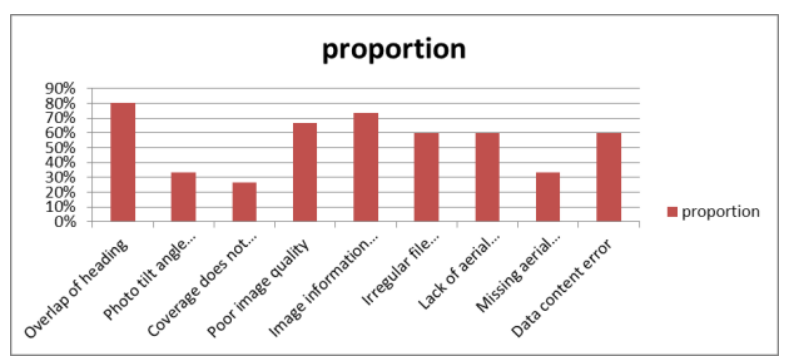

Figure 4. 15 project case quality error and omission ratio statistics chart

As can be seen from the above figure, the results of surveying and mapping aerial photography are currently in the level of flight quality, image quality, data quality and accessory quality. There are many problems, combined with the development of the industry and the research situation, the following will analyze the quality problems and the corresponding improvement methods.

(1) Increase the inspection of various indicators of flight quality In the problem of quality of results, the error rate of flight quality is the highest among various inspection items, such as heading overlap degree, side overlap degree, image

There are over-limit problems in the inclination angle, rotation angle, course curvature, image point displacement, and flight height difference, especially when the heading overlap degree reaches $80 \%$. This part of errors and omissions can be effectively checked by the manufacturer's own software or professional quality inspection software, and unqualified routes or areas can be found in time, which can greatly improve the efficiency of quality inspection and ensure the quality of results.

(2) Regulate airspace application and aerial photographing data submission for review

Due to restrictions on project production costs, project production cycles, and airspace application processing cycles, there are currently many aerial photography projects that fail to apply for airspace in accordance with the regulations. This is an imbalance with the rapid development of aerial photography technology at this stage. Although some existing laws and regulations involve some No-fly regulations or temporary control measures for drones, but the timeliness and standards vary. To standardize the order of drone management, it is urgent to issue special laws and regulations at the national level to strictly regulate all links such as operation and sales, qualification certification, flight application, tracking supervision, and accountability to ensure that the flight is controlled by law and the flight is governed by law. In addition, we should continue to strengthen the publicity and education of air defense safety and the rule of law to ensure that the public becomes familiar with and strictly abide by general aviation management policies and regulations as soon as possible, understand the relevant regulations of flight approval, and truly form a good situation of group defense and group governance.

(3) Pay attention to the verification of the correctness of the parameter settings before the flight

The results of aerial photogrammetry are not like ordinary project production. Retesting after quality problems is found will lead to a large increase in cost and relatively difficult to implement. For this reason, there are many softwares on the market that control flight parameters, as well as aerial photography. Carry together, real-time adjustment of various parameters during the flight. Strictly requiring operators to set parameters in accordance with the specifications and check and confirm before the flight is an important way to improve the quality of the industry.

(4) Incorporate aerial photography projects into the scope of annual qualification unit spot checks

In recent years, the Ministry of Natural Resources has organized and carried out annual supervision and random inspections of qualified units, which has played a very important role in improving the quality awareness of the industry. It has conducted annual random inspections on units, companies and enterprises in various fields such as surveying and mapping, geology, and can timely grasp the quality development status of the industry, And through corresponding punishment measures, effectively promote the standardized development of the company's corporate quality management work, especially the technological advancement and the rapid development of aerial photography in the industry, which need to be guided by "supervision" hands.

\section{CONCLUSIONS}

This article uses the quality inspection of aerial photogrammetry results for surveying and mapping to promote the quality of the industry as the goal, mainly to complete or obtain the following results:

(1) Complete the current stage of the analysis and research on the quality inspection standards of aerial photography results, analyze the commonly used national standards, industry standards and their application, and finally adopt the frame-type digital aerial photography results and push-broom digital aerial photography results in the industry standards. Detailed division of quality elements of photographic results and inspection items and other provisions.

(2) Combining with the development of specific quality inspection work, the method for quality inspection of aerial photography results was elaborated, and the inspections and points for attention in airspace application materials, flight quality, and image quality were analyzed.

(3) Combining the collected 15 aerial photography projects, carried out the summary and analysis of quality errors and omissions, which can reflect the current quality status of the industry to a certain extent 。

(4) Focusing on common quality errors and omissions, combined with actual causes, four quality improvement measures are proposed, which are of great significance to the development of subsequent aerial photography projects and the improvement of quality in this field.

The research content and results of this article can provide reference for the quality inspection of aerial photography results and the quality control of project production.

\section{REFERENCES}

Geng, L., Zhang, J., Gong W., 2010: Experimental Research on Aerial Triangulation for DMC Aerial Photograph. Geomatics \& Spatial Information Technology 33(04), 206-208+214. 
Hhle, J., 2009: DEM Generation Using a Digital Large Format Frame Camera. Photogrammetric Engineering and Remote Sensing 75 (1), 87-93

Hong, L., Wang H., Cao, J., 2013: Discussion of Quality Inspection Technology of Aerial Photography Products. Geomatics and Information Science of Wuhan University 38(10), 1172-1174.

Liao Anping et al.2013: CH/T 1029.2-2013 Technical regulations for quality inspection and acceptance of aerial photography results- Part 2: Frame digital aerial photography[S] Beijing: Standards Press of China, 2013

Liao Anping et al.2013: CH/T 1029.3-2013 Technical regulations for quality inspection and acceptance of aerial photography results- Part 3: Push-broom digital aerial photography

Tang, R., Fritsch, D., 2012: Cramer M.New Rigorous and Flexible Fourier Self-calibration Models for Airborne Camera Calibration. ISPRS Journal of Photogrammetry and Remote Sensing, 71 (7) :76-85

Zeng, Y., et al.2009:GB/T 24356-2009 Specifications for Quality Inspection and Acceptance of Surveying and Mapping Products[S].Beijing: Standards Press of China, 2009 